\title{
Immigrants in the Netherlands: Equal access for equal needs?
}

\author{
K Stronks, A C J Ravelli, S A Reijneveld
}

\begin{abstract}
Objective-This paper examines whether equal utilisation of health care services for first generation immigrant groups has been achieved in the Netherlands.

Design-Survey data were linked to an insurance register concerning people aged 16-64. Ethnic differences in the use of a broad range of health care services were examined in this group, with and without adjustment for health status and socioeconomic status, using logistic regression.

Setting-Publicly insured population in Amsterdam, the Netherlands.

Participants-1422 people from the indigenous population, and 378 people from the four largest immigrant groups in the Netherlands-that is, the Surinamese, the Netherlands Antilleans, and the Turkish
\end{abstract} and Moroccan.

Main outcome measures-General practitioner service use (past two months), prescription drug use (past three months), outpatient specialist contact (past two months), hospital admission (past year), physiotherapist contact (past two months) and contact with other paramedics (past year).

Main results-Ethnicity was found to be associated with the use of health care after controlling for health status as an indicator for need. The use of general practitioner care and the use of prescribed drugs was increased among people from Surinam, Turkey and Morocco as compared with the indigenous population. Compared with the indigenous group with corresponding health status, the use of all other more specialised services was relatively low among Turkish and Moroccan people. Among the Surinamese population, the use of more specialised care was highly similar to that found in the Dutch population after differences in need were controlled for. Among people from the Netherlands Antilles, we observed a relatively high use of hospital services in combination with underuse of general practitioner services. The lower socioeconomic status of immigrant groups explained most of the increased use of the general practitioner and prescribed drugs, but could not account for the lower use of the more specialised services.

Conclusions-The results indicate that the utilisation of more specialised health care is lower for immigrant groups in the Netherlands, particularly for Turkish and Moroccan people and to a lesser extent, people from the Netherlands Antilles. Although underuse of more specialised services is also present among the lower socioeconomic groups in the Netherlands, the analyses indicate that this only partly explains the lower utilisation of these services among immigrant groups. This suggests that ethnic background in itself may account for patterns of consumption, potentially because of limited access.

(F Epidemiol Community Health 2001;55:701-707)

Equality with respect to health care is a major political issue in Western European countries. For example, in the debate on health care reform, the general accessibility of "basic services", irrespective of someone's income, age, ethnic group, etc, is frequently discussed. ${ }^{1}$ Whether equal accessibility has been realised can be studied empirically by comparing differences in the use of medical care controlling for potential differences in health status. If the use of health care by different groups in the population is in accordance with differences in health status between these groups, the principle of equal treatment for equal need can be said to be realised. ${ }^{2}$ This paper examines whether equal use of health care has been achieved in the Netherlands. It focuses on one dimension of equality in particular, namely equality between ethnic groups.

The number of immigrants in the Netherlands is growing. Currently, they constitute approximately $9 \%$ of the population. The four largest immigrant groups are comprised of people from Surinam, the Netherlands Antilles and Turkey and Morocco. Surinam is a former Dutch colony. Most Surinamese migrated to the Netherlands during the process of decolonisation (1975). The Netherlands Antilles are still part of the Dutch state. The Mediterranean groups - that is, the Turkish and Moroccans - have come to the Netherlands as labour migrants since the 1960s and early 1970s.

It is still unknown whether the use of health care in these immigrant groups is in accordance with their relatively bad health status. ${ }^{3}$ Studies in other European countries, especially the United Kingdom, indicate that primary care services are more frequently used by ethnic minority groups (controlling for differences in health status) while their use of outpatient services is lower. ${ }^{245}$ The number of services analysed in previous studies however is limited, for example we do not know whether the pattern of lower consumption is also present in regard to the use of physiotherapists. Moreover, most previous analyses are based on 
self reported data on utilisation of health care. ${ }^{2}$ There are indications, however, that the cross cultural validity of these data is suboptimal. ${ }^{6}$ In the analyses presented in this paper, both drawbacks will be overcome by using registration data from a health insurance company.

The first aim of the analyses was to examine to what extent the ideal of equal utilisation of health care is realised for the four largest immigrant groups in Amsterdam, the Netherlands. The second aim concerns the explanation of (probable) ethnic differences in the use of health care. The above mentioned pattern of overconsumption of primary care services and underconsumption of specialised services is very similar to that found for lower socioeconomic groups. ${ }^{7}$ As people from immigrant groups in general have a lower socioeconomic position than the indigenous population, this raises the question of whether the problem of ethnic inequalities in the use of health care is simply the consequence of the lower socioeconomic position of immigrant groups, or whether their ethnic background in itself also plays a part.

In summary, the main questions investigated in this paper are the following:

(1) Are there differences between ethnic minority groups in the use of a broad range of health care services after controlling for health status?

(2) If so, to what extent are these differences related to the generally lower socioeconomic position of immigrant groups?

\section{Methods}

The study is based on a linkage of data from a health insurance company and data from a health survey among the general population in Amsterdam, the Netherlands.

POPULATION

An a-select sample of non-institutionalised people was drawn from the Amsterdam municipal population register, aged 16 years and older. The sample was stratified by age (16-34, 35-64, 65 years and over). The analyses that are reported in this paper are restricted to people aged 16-64, as the oldest age group contained very few immigrants. During 1992 and 1993 the people in this sample were interviewed at home in either Dutch, Arabic, Turkish or English. The interview consisted of questions concerning health problems, use of health care services, socioeconomic status and other health determinants. The response rate among the population aged 16-64 was $60.6 \%$, resulting in a study population of 3296 people, with small differences across ethnic groups (55.7 in the Surinamese to 61.7 in the indigenous population) and other subgroups (for example, age and sex). The design and objectives of the health survey have been described in detail elsewhere. ${ }^{8}$

A total of 2012 of these respondents could be linked to the administration of the public insurance fund register in Amsterdam, using postcode, date of birth and sex as keys. The linkage procedure has been described in detail elsewhere. ${ }^{6}{ }^{9}$ The percentage of imperfect linkages was expected to be very small, as the linkage key we used was very specific. The data on this key in both registers concerned the same period and the data in both registers were up to date. ${ }^{9}$ Those who could not be linked were either not insured by this company or were only insured during a part of the period covered by the survey. Public insurance is obligatory for lower income groups-that is, approximately $70 \%$ of the Amsterdam population. Among people for whom we had data from the survey as well as the health insurance company, 139 were Surinamese, 25 Antillean, 129 Moroccan, 85 Turkish, and 1422 native born. Some 412 were born in other countries than the four selected here.

\section{MEASUREMENTS}

The ethnic background of the respondents was indicated according to their country of birth as registered in the Amsterdam municipal register.

Health care use was based on registration data from the health insurance registration process. This recorded claims for various types of care in the period preceding the point of the interview, paid for by the health insurance fund to a health care provider, on a fee for service basis. The services included in the analyses are mentioned in table 1. Data on general practitioner service use could not be derived from the health insurance registration, as the general practitioner is not paid for on a fee for service basis. These data are instead based on self report. All utilisation variables were dichotomised.

Data on health status were also based on self report. The time frame chosen for the measurement of health problems was similar to that for the use of health care. Four indicators were used-that is, self rated health, health complaints, short term physical limitations and chronic conditions. ${ }^{10}$ The operationalisation and categorisation of these variables is explained in table 1 .

Socioeconomic status was indicated by educational level, occupational status and income. These are considered to be valid indicators of socioeconomic status. ${ }^{11}$ Educational status refers to the highest educational level attained. It is considered the single most powerful indicator in the native population, and therefore frequently used as the only indicator. However, as a large proportion of the immigrant groups have primary school only, we decided to include all socioeconomic indicators that were available. The occupational status of the respondent was determined on the basis of the current occupation if in paid employment, or if not, the last employment. Income was indicated by household income, adjusted for the number of persons inside the household who had to live from the income (one or more). The categorisation and operationalisation of these three socioeconomic indicators is explained in table 1 .

Age (10 year categories) and sex were taken into account as confounding variables. The 
Table 1 Measurements included in the study

\begin{tabular}{|c|c|c|c|}
\hline Variable & Operationalisation & Categories used in analyses & Source \\
\hline $\begin{array}{l}\text { Ethnic background } \\
\text { Use of health care }\end{array}$ & Country of birth & Surinamese, Antillean, Turkish, Moroccan, native Dutch & Municipal register \\
\hline General practitioner & Use past 2 months & Any versus no use & Health interview survey \\
\hline Prescription drug use & Use past 3 months & Any versus no use & Health insurance register \\
\hline Hospital admission & Use past year & Any versus no use & Health insurance register \\
\hline Outpatient specialist & Use past 2 months & Any versus no use & Health insurance register \\
\hline Physiotherapist & Use past 2 months & Any versus no use & Health insurance register \\
\hline $\begin{array}{l}\text { Other paramedics } \\
\text { Health status }\end{array}$ & Use past year & Any versus no use & Health insurance register \\
\hline Self rated health & How do you rate your health in general? & (very) good versus less than good & Health interview survey \\
\hline Health complaints & Checklist, containing 20 minor complaints & $<4$ versus $\geqslant 5$ & Health interview survey \\
\hline Chronic conditions & Checklist, containing 7 chronic conditions & 0 versus $\geqslant 1$ & Health interview survey \\
\hline Days ill in bed & Past two months & 0.1 versus $>1$ & Health interview survey \\
\hline $\begin{array}{l}\text { Socioeconomic status } \\
\text { Education }\end{array}$ & & & \\
\hline Education & Highest level attained & 3 educational levels ${ }^{\star}$ & Health interview survey \\
\hline Income & Household, equivalent & 3 income levels $†$ & Health interview survey \\
\hline Occupational level & Current/last paid employment & 5 occupational levels + not in paid employment $\ddagger$ & Health interview survey \\
\hline
\end{tabular}

*The educational levels were: primary school only; general education and lower/intermediate vocational training; higher vocational college and university. $†$ The income levels were: less than 1900 Dutch guilders a month, 1900-4000 guilders a month, more than 4000 guilders a month. $\ddagger$ The occupations were classified according to the five levels outlined in the Erikson, Goldthorpe and Partocarero (EGP) scheme ${ }^{12}$ - that is, higher grade professionals; lower grade professionals and routine nonmanual employees; self employed; high and low skilled manual workers; unskilled manual workers. The persons who had never been in paid employment formed the sixth category.

interactions between age and sex were tested for statistical significance.

ANALYSES

We used logistic regression models, given the dichotomous outcome variables. For each outcome measure, a basic model was first fitted containing ethnic background as an independent variable, controlling for age and sex (model 1). Ethnic differences in the use of health were expressed as odds ratios (ORs) with corresponding $95 \%$ confidence intervals. The indigenous population was used as a reference category. Interactions between country of birth and sex, and country of birth and age were examined separately.

Secondly, the health status indicators were added to the first model to control for need (model 2). The reduction in ORs after controlling for health status was used to indicate the contribution of health status to ethnic differences in health care utilisation. If ethnicity seems to be a determinant of utilisation, this indicates that equality has not been achieved.

Finally, to estimate to what extent the remaining ethnic differences in utilisation were attributable to the relatively low socioeconomic position of immigrants in the Netherlands, the socioeconomic indicators were added to the second model. If the OR still differed from 1 , this would imply that the underconsumption or overconsumption as observed in model 2 could not completely be accounted for by differences in socioeconomic position between the immigrant and indigenous population.

The analyses were carried out using SPSS 8 for Windows.

\section{Results}

As expected, the health status of the immigrant groups was worse than that of the indigenous population (table 2). Especially Turkish and Moroccan people are (statistically significantly) more likely to rate their health as less than "good" or to report health complaints. Also as far as their socioeconomic status is concerned, the immigrant groups are in an adverse position. In particular, the percentage of Turkish and Moroccan people with primary school only is very high (84.7 and $63.6 \%$ respectively versus $24.7 \%$ in the indigenous population).

Table 3 shows the use of health services by ethnic group, indicated by the percentage of people making any use of that specific service. All immigrant groups are more likely to consult a general practitioner and to use prescribed drugs than the indigenous population, the only exception being people from the Antilles among whom contact with the general practitioner especially is less frequent (12.0 versus $17.4 \%$ in the indigenous population). The prevalence of general practitioner use is especially high among Turkish and Moroccan

Table 2 Percentage of persons in selected category of demographic factors, health status and socioeconomic status, by ethnic group, standardised for age and sex, total population $(n=2012)$

\begin{tabular}{|c|c|c|c|c|c|c|}
\hline & Indigenous & Surinam & $\begin{array}{l}\text { Netherlands } \\
\text { Antilles }\end{array}$ & Turkey & Morocco & Total \\
\hline Number & 1422 & 139 & 25 & 85 & 129 & 2012 \\
\hline \multicolumn{7}{|l|}{ Demographic factors } \\
\hline$<35$ years old & 46.6 & 45.3 & 48.0 & 62.4 & 48.1 & 47.1 \\
\hline$>55$ years old & 18.3 & 10.1 & 4.0 & 3.5 & 7.0 & 15.0 \\
\hline men & 44.0 & 32.4 & 40.0 & 51.8 & 58.1 & 44.9 \\
\hline \multicolumn{7}{|l|}{ Health status } \\
\hline 'less than good' self rated health & 22.5 & 29.6 & 17.8 & 48.4 & 41.7 & 25.9 \\
\hline$\geqslant 5$ health complaints & 31.1 & 35.3 & 25.7 & 61.8 & 54.5 & 36.4 \\
\hline$\geqslant 1$ chronic conditions & 22.5 & 24.4 & 13.5 & 41.4 & 42.5 & 25.0 \\
\hline$>1$ days ill in bed & 11.5 & 8.2 & 7.9 & 16.7 & 17.6 & 12.0 \\
\hline \multicolumn{7}{|l|}{ Socioeconomic status } \\
\hline Primary education only & 23.4 & 28.3 & 25.1 & 80.2 & 60.5 & 30.3 \\
\hline Lowest income group & 27.9 & 47.4 & 26.0 & 51.2 & 44.6 & 33.0 \\
\hline Lowest occupational level & 21.5 & 24.2 & 13.0 & 54.7 & 54.7 & 24.8 \\
\hline
\end{tabular}

Percentages that are statistically significantly different from the indigenous population are printed in italic (assessed with $\chi^{2}, \mathrm{p}<0.05$ ). 
Table 3 Utilisation of health services by ethnic group: percentage of users, standardised for age and sex, total population $(n=2012)$

\begin{tabular}{lllllll}
\hline & Indigenous & Surinam & $\begin{array}{l}\text { Netherlands } \\
\text { Antilles }\end{array}$ & Turkey & Morocco & Total \\
\hline $\begin{array}{l}\text { Number } \\
\begin{array}{l}\text { Health service } \\
\text { general practitioner }\end{array}\end{array}$ & 1422 & 139 & 25 & 85 & 129 & 2012 \\
$\begin{array}{l}\text { prescription drug use } \\
\text { hospital admission }\end{array}$ & 45.2 & 23.7 & 6.6 & 39.2 & 37.3 & 21.0 \\
$\begin{array}{l}\text { outpatient specialist } \\
\text { physiotherapist }\end{array}$ & 8.3 & 5.6 & 28.4 & 58.6 & 66.5 & 49.5 \\
other paramedics & 18.0 & 6.0 & 17.4 & 4.8 & 7.5 & 7.3 \\
\hline
\end{tabular}

Percentages that are statically significantly different from the indigenous population are printed in italic (assessed with $\chi^{2}, \mathrm{p}<0.05$ ).

Table 4 Utilisation of health care by ethnic background, as assessed by logistic regression models; the indigenous population is used as the reference category ${ }^{\star}$ (odds ratios and $95 \%$ confidence intervals; significantly increased odds ratios in italic)

\begin{tabular}{|c|c|c|c|c|}
\hline & Surinam $(n=139)$ & $\begin{array}{l}\text { Netherlands } \\
\text { Antilles }(n=25)\end{array}$ & Turkey $(n=85)$ & Morocco $(n=129)$ \\
\hline \multicolumn{5}{|c|}{ General practitioner } \\
\hline model 1 & $1.52(1.00,2.30)$ & $0.67(0.20,2.26)$ & $3.07(1.92,4.92)$ & $3.33(2.26,4.91)$ \\
\hline model 2 & $1.31(0.83,2.07)$ & $0.46(0.12,1.70)$ & $1.48(0.87,2.53)$ & $2.25(1.44,3.51)$ \\
\hline model 3 & $1.20(0.75,1.92)$ & $0.44(0.11,1.68)$ & $1.13(0.64,1.99)$ & $1.66(1.02,2.71)$ \\
\hline \multicolumn{5}{|c|}{ Prescription drug use } \\
\hline model 1 & $1.57(1.09,2.26)$ & $1.13(0.50,2.54)$ & $2.20(1.38,3.50)$ & $2.17(1.47,3.18)$ \\
\hline model 2 & $1.46(1.00,2.13)$ & $1.03(0.45,2.40)$ & $1.50(0.92,2.47)$ & $1.72(1.14,2.58)$ \\
\hline model 3 & $1.43(0.97,2.10)$ & $0.96(0.41,2.25)$ & $1.10(0.65,1.85)$ & $1.39(0.89,2.16)$ \\
\hline \multicolumn{5}{|c|}{ Hospital admission } \\
\hline model 1 & $1.19(0.62,2.29)$ & $3.71(1.35,10.2)$ & $0.98(0.38,2.49)$ & $1.37(0.71,2.66)$ \\
\hline model 2 & $1.10(0.57,2.15)$ & $3.73(1.31,10.6)$ & $0.65(0.25,1.70)$ & $0.98(0.49,1.96)$ \\
\hline model 3 & $1.07(0.54,2.11)$ & $3.68(1.26,10.7)$ & $0.55(0.20,1.48)$ & $0.78(0.37,1.66)$ \\
\hline \multicolumn{5}{|c|}{ Outpatient specialist } \\
\hline model 1 & $0.97(0.51,1.86)$ & $1.03(0.24,4.43)$ & $1.22(0.57,2.60)$ & $0.98(0.50,1.93)$ \\
\hline model 2 & $0.89(0.46,1.71)$ & $0.94(0.21,4.12)$ & $0.82(0.37,1.79)$ & $0.74(0.37,1.79)$ \\
\hline model 3 & $0.95(0.49,1.86)$ & $0.91(0.20,4.05)$ & $0.77(0.34,1.77)$ & $0.72(0.34,1.52)$ \\
\hline \multicolumn{5}{|c|}{ Physiotherapist } \\
\hline model 1 & $1.32(0.86,2.02)$ & $0.42(0.10,1.81)$ & $1.21(0.69,2.15)$ & $0.82(0.48,1.38)$ \\
\hline model 2 & $1.20(0.77,1.85)$ & $0.36(0.08,1.61)$ & $0.75(0.41,1.37)$ & $0.58(0.33,1.00)$ \\
\hline model 3 & $1.25(0.80,1.95)$ & $0.37(0.08,1.66)$ & $0.85(0.45,1.59)$ & $0.67(0.37,1.20)$ \\
\hline \multicolumn{5}{|c|}{ Other paramedics } \\
\hline model 1 & $1.18(0.78,1.79)$ & $0.56(0.17,1.90)$ & $1.04(0.59,1.83)$ & $0.75(0.45,1.25)$ \\
\hline model 2 & $1.06(0.69,1.63)$ & $0.49(0.14,1.72)$ & $0.63(0.35,1.15)$ & $0.52(0.30,0.89)$ \\
\hline model 3 & $1.11(0.72,1.72)$ & $0.51(0.14,1.83)$ & $0.68(0.36,1.26)$ & $0.57(0.32,1.02)$ \\
\hline
\end{tabular}

*Model 1: confounders only (age and sex). Model 2: confounders + health status indicators (self rated health, health complaints, days ill in bed, chronic conditions). Model 3: confounders + health status indicators + socioeconomic status indicators (educational and income level, and occupational status).
KEY POINTS

- In the Netherlands, equality with respect to health care has not yet been realised for immigrant groups: the utilisation of more specialised health care is lower in these groups than in the indigenous population.

- This inequality in utilisation is not accounted for by the lower socioeconomic position of immigrants groups alone.

- This implies that the ethnic background in itself may be a factor that affects the utilisation of health care and thus accounts for differences in consumption pattern between immigrant groups and the indigenous population.

- Additional measures are warranted to further improve the accessibility of health care in immigrant groups.

the figures controlling for age and sex only. The pattern of ethnic differences was similar to that as observed in table 2-that is, higher rates among immigrants for general practitioner and prescribed drugs use, and very little differences for the other services. The interactions of ethnicity with age and sex seemed to be statistically significant in the case of general practitioner use (table 5). This seemed to be especially high among people aged 35-64 and among the male immigrants.

In the second model, health status is controlled for as an indicator for need (table 4). Controlling for differences in health status reduces the higher utilisation rate of general practitioner care and of prescription drug use among the Surinamese, Turkish and Moroccan people, but the ORs are still higher than those among the indigenous population, although only statistically significant among the Moroccan in the case of use of the general practitioner.

For all groups except the Surinamese, the pattern for those services where consumption in the first model showed few differences from the indigenous population, now reverses, although most differences are not statistically significant. This applies to hospital and specialist care (Turkish and Moroccan people), as well as physiotherapist use and use of other paramedics (Turkish, Moroccan and Antillean people). The pattern among the Antillean group now is very similar to the Turkish and Moroccan people. After controlling for health status, the higher use of hospital care is however still observed in this group. The

Table 4 shows the results of the logistic regression models, the first model indicating

Table 5 Utilisation of general practitioner care by ethnic background, by age and sex, as assessed by logistic regression models; the indigenous population is used as the reference category* (odds ratios and $95 \%$ confidence intervals; significantly increased odds ratios in italic)

\begin{tabular}{lllll}
\hline & Surinam & Netherlands Antilles & Turkey & Morocco \\
\hline $\begin{array}{l}\text { Total population } \\
\text { By age group } \dagger\end{array}$ & $1.52(1.00,2.30)$ & $0.67(0.20,2.26)$ & $3.07(1.92,4.92)$ & $3.33(2.26,4.91)$ \\
16-34 years old & $0.66(0.29,1.50)$ & $0.48(0.06,3.76)$ & $1.74(0.88,3.45)$ & $2.74(1.52,4.95)$ \\
35-64 years old & $2.30(1.38,3.83)$ & $0.78(0.17,3.58)$ & $6.03(2.89,12.58)$ & $3.78(2.24,6.36)$ \\
By sex $\neq$ & & & & \\
Men & $1.91(0.92,3.97)$ & $0.59(0.07,4.75)$ & $4.15(2.13,8.09)$ & $4.81(2.84,8.16)$ \\
Women & $1.37(0.83,2.28)$ & $0.68(0.15,3.06)$ & $2.18(1.10,4.30)$ & $2.17(1.20,3.92)$ \\
\hline
\end{tabular}

^Controlled for age and sex. †Controlled for sex. $\ddagger$ Controlled for age. 
consumption pattern for specialised care in the Surinamese population is now similar to that in the native born population.

Finally, in the third model, the remaining differences in health care utilisation are controlled for differences in socioeconomic position (table 4). This further reduces the higher frequency of general practitioner and prescription drug use especially among Turkish and Moroccan people. The only statistically significant increased OR is now observed for Moroccan people in the case of general practitioner use. In contrast, the lowered rates of hospital admission, outpatient specialist use, and use of physiotherapist and other paramedics observed in the second model barely change after controlling for socioeconomic status. In addition, the higher hospital admission rate among people from the Netherlands Antilles remains highly significant, although the confidence intervals are wide.

\section{Discussion}

The aim of the analyses presented in this paper was (1) to assess whether there are ethnic differences in the use of health care after differences in health status have been controlled for, and (2) to obtain more insight into the possible role of socioeconomic status in the explanation of ethnic inequalities in the use of health care. Ethnicity was found to be associated with the use of health care after controlling for health status as an indicator for need, especially among the Turkish and Moroccan immigrants. Prescribed drugs and general practitioner care was used more frequently but most other services were used less frequently than by the indigenous population with similar health status, although differences were statistically significant for Moroccan people only. Among the total Surinamese population, health care use was similar to that found in the Dutch population after differences in need were controlled for, although among older Surinamese people the use of general practitioner care was higher than in the indigenous population. The excess use of hospital services among people from the Netherlands Antilles, in combination with underconsumption in regard to general practitioner use was striking. The lower socioeconomic position of immigrant groups explained most of their increased use of the general practitioner services and prescribed drugs, but could not account for the lowered use of the other services. Although the data have been obtained in 1992/3, we expect the results to be valid nowadays, as more recent studies on some of the ethnic groups and some health services included here point out a similar pattern of overconsumption and underconsumption. ${ }^{13}$

Before interpreting the results, some potential limitations should be considered. Firstly, the numbers of immigrants involved in the analyses were small, yielding broad confidence intervals. However, when the same analyses were carried out in a larger population (results not shown), including the entire group that was included in the sample and registered in the administration of the health insurance company in $1992 / 3$, the ethnic variation in the use of health care (controlling for age and sex) was highly similar to that observed in the more limited dataset, with the ORs being more frequently statistically significant. For example, among Moroccan immigrants, the OR for hospital admission was $0.57(0.33,0.99)$, and for use of (other) paramedics $0.64(0.45,0.92)$. Unfortunately, because in that dataset data on health status and socioeconomic position were missing for part of the population (that is, those people not interviewed), it could not be used for the research questions that were central to this paper.

Secondly, there is a possibility that the increased use observed for general practitioner and prescription drug use is attributable to an insufficient adjustment for health status. This could be the case if the indicators included do not cover the whole range of health problems, or if the report of health problems differ between ethnic groups. These assumptions are not very likely, however, as the health indicators included in the analyses did affect the ORs with respect to those services for which underconsumption was observed. Moreover, controlling for other health indicators such as the score on the General Health Questionnaire (GHQ), did not yield a further change in ORs (results not shown). Similar reasoning applies to a probably insufficient adjustment for socioeconomic status in the case of services that were used less frequently among immigrants, as controlling for socioeconomic differences partly account for the pattern of overconsumption.

Finally, the pattern of overconsumption in the case of general practitioner use and underconsumption with respect to the other services, might be the consequence of the fact that different sources of information were used, as the data on general practitioner use were based on self report. When, however, the analyses as reported here were repeated using self reported data for all outcome measures, we observed a similar pattern of relatively high use of primary care, and relatively low use of more specialised care (results not shown). This seems to imply that self reported data on health care use are a useful method for providing a valid estimation of ethnic differences in health care use. ${ }^{6}$

The (unadjusted) differences in the use of medical care as observed here are highly similar to those observed in previous studies in the Netherlands. ${ }^{13}$ Compared with earlier studies, this research introduces a new element concerning the control for differences in health status as an indicator for need. Our analyses confirmed the finding that was observed in several other countries - that is, a higher use of general practitioner services combined with lower use of more specialised services. ${ }^{2}$ In comparison with previous studies, however, this study considers a broader range of services, including use of physiotherapists and other paramedics as well as hospital admission. These services were also less frequently used by immigrant groups compared with the group 
with a corresponding health status in the indigenous population, although not statistically significantly. Therefore the results of this study seem to suggest that underuse rather than overuse is the characteristic pattern for most immigrant groups in the Netherlands. We expect this conclusion to apply to the whole immigrant population in the Netherlands despite the fact that only the publicly insured were included in the study reported here. The reason is that the majority of the immigrant population in the Netherlands belong to the lower income groups, and are thus publicly insured. This view is supported by the results of the health interview survey showing that the proportion of publicly insured varies between $85 \%$ among the Surinamese and $96 \%$ among the Moroccan subgroup.

The results of this study also provide indications with respect to the underlying mechanisms that might account for these ethnic differences. Although underuse of more specialised services is also present among lower socioeconomic groups in the Netherlands in general, ${ }^{7}$ the results of our analyses do not provide indications to suggest that the low socioeconomic position of most immigrants accounts for this underuse. This implies that their ethnic background in itself may be a factor that accounts for their consumption pattern, potentially because of a limited access of health care services for immigrant groups. However, this study does not provide clear indications as to the explanation of this probable inequality in accessibility of services. Possible explanations relate to the communication between the physician and the immigrant patient, with regard to language problems and cultural aspects. These hypotheses should be tested in future research.

It should be mentioned that the fewer contacts with for example specialists and physiotherapists as well as the lower hospital admission rates do not necessarily have a negative effect upon the health status of the immigrant groups. Firstly, we cannot be sure that the level of utilisation in the indigenous population, which is used as the reference, reflects the adequate level of health care use and can therefore be considered an adequate gold standard. Furthermore, even if the consumption in the indigenous population does serve as an adequate gold standard, it might be possible that the lower use of some services among immigrants is compensated by, for example, the higher use of general practitioner services. In addition, there is a possibility that the use of informal alternatives to the Dutch health care services, or the use of health care in the country of origin, might compensate for the lower use of specific services in the Netherlands. Thus further research is necessary to study whether differences in health care consumption between ethnic groups lead to a worse health outcome among ethnic minority groups.

In the Netherlands, the high utilisation of practitioner care and prescribed drug use among immigrants is frequently mentioned as a problem. We have shown, however, that this higher use is partly accounted for by the worse health status of immigrants (although the utilisation rates among Moroccans were still increased after controlling for health status as an indicator for need). This pattern of increased use seemed to be present in the older age groups in particular.

The relatively high use of general practitioner services are also found in lower socioeconomic groups generally in the Netherlands. ${ }^{7}$ The results of this study provide evidence to suggest that these socioeconomic differences in the use of health services account for most of the increased use of specific services among immigrants. This implies that the explanation for the increased use among immigrants is similar to the explanation for the corresponding socioeconomic differences. Explanations that have been suggested for this pattern include differences in attitudes between socioeconomic strata. For example, people with a lower education, in the indigenous as well as the immigrant population, might be more inclined to visit the general practitioner with minor complaints.

The statistically significantly higher probability of hospital admission seemed to be typical for people from the Netherlands Antilles, although it should be mentioned that the number of respondents in this ethnic group was rather small. Probable explanations for this include the different role of hospital care in the Antilles. Moreover, it has been suggested that people living overseas come to the Netherlands for an operation, using the legitimisation of a family member or friend living in the Netherlands.

In summary, the results seem to suggest that, in the Netherlands, the ideal of equal use according to equal need has not yet been achieved with respect to ethnic minority groups. Future research should indicate whether the same pattern is found in other countries and whether these ethnic differences in health care use are indeed attributable to an inequality in the access to health care. Given the potential mechanisms underlying this inequality, it might be expected that the situation improves when immigrant groups become more integrated in society, at least as far as inequality is related to ethnic background rather than their socioeconomic position. In the United States for example, no differences in health care use were found between the indigenous population and immigrants living there for 10 years or more. ${ }^{14}$ The first generation, however, still forms the largest proportion of immigrants in the Netherlands, implying that additional measures are warranted to further improve the accessibility and therefore the quality of care in these groups.

Funding: the fieldwork of this study was financially supported by the Municipality of Amsterdam, eight submunicipal authorities ("stadsdeelraden"), the Amsterdam Municipal Health Service (GG\&GD), and the Amsterdam Social Health Insurance Company (ZAO). The analysis were financially supported by the Amsterdam Social Health Insurance Company (ZAO), the Amsterdam Academic Medical Centre, and TNO Prevention and Health.

Conflicts of interests: none. 
1 Gunning-Schepers LJ, Kronjee GJ, Spassof RA, eds. Fundamental questions about the future of health care (conference ntific Council for Government Policy, 1996.

2 Smaje C, Le Grand J. Ethnicity, equity and the use of health services in the British NHS. Soc Sci Med 1997;45:485-96

3 Uniken Venema HP, Garretsen HFL, Maas PJ van der. Health of migrants and migrant health policy, the Netherlands as an example. Soc Sci Med 1995;41:809-18.

4 Cooper H, Smaje C, Arber S. Use of health services by children and young people according to ethnicity and social class: secondary analysis of a national survey $B M^{\mathcal{F}}$ 1998:317:1047-51.

5 Peterson ED, Shaw LK, DeLong ER, et al. Racial variation in the use of coronary revascularization procedures. $N$ Engl 7 Med 1997;336:480-6.

6 Reijneveld SA. The cross-cultural validity of self-reported use of health care: a comparison of survey and registration use of health care. a comparison of surve

7 Meer J van der. Equal care, equal cure? Socioeconomic differences in the use of health services and the course of health problems. [PhD thesis]. Rotterdam: Erasmus University, 1998.
8 Reijneveld SA. Reported health, lifestyles, and use of health care of first generation immigrants in the Netherlands: do care of first generation immigrants in the Netherlands: do
socioeconomic factors explain their adverse position. $\mathcal{F}$ Episocioeconomic factors explain their adverse pos
demiol Community Health 1998;52:298-304.

9 Reijneveld SA, Stronks K. The impact of response bias on estimates of health care utilisation in a metropolitan area: a study using administrative data. Int $\mathcal{F}$ Epidemiol 1999;28: $1134-40$.

10 Netherlands Bureau of Statistics. Netherlands Health Interview Survey 1981-1991. The Hague: SDU Publishers, 1992.

11 Liberatos P, Link BG, Kelsey JL. The measurement of social class in epidemiology. Epidemiol Rev 1988;10:87-121.

12 Erikson R, Goldthorpe JH, Portocarero L. Intergenerational class mobility and the convergence thesis: England, France and Sweden. Br F Sociol 1983;34:303-43.

13 Weide M. Gezondheidszorg in de multiculturele samenleving; een overzicht van onderzoek naar de toegankelijkheid en kwaliteit van zorg voor migranten. [In Dutch]. Paper Onderzoeksprogramma Cultuur en Gezondheid. Den Haag: NWO/ ZON 1998 .

14 Leclere FB, Jensen L, Biddlecom AE. Health care utilization, family context, and adaptation among immigrants in the United States. F Health Soc Behav 1994;35:370-84

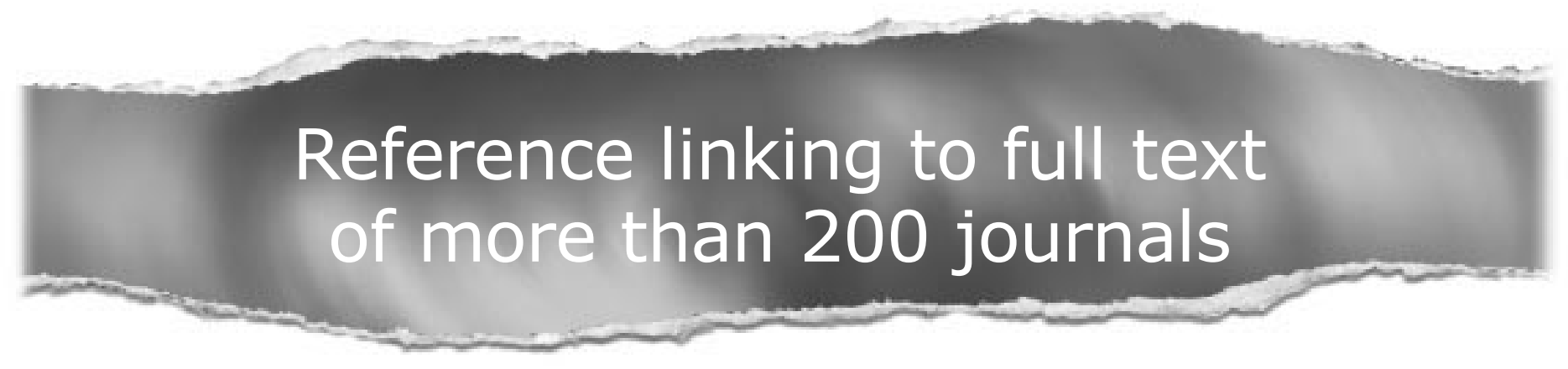

Toll free links

You can access the FULL TEXT of articles cited in the Journal of Epidemiology and Community Health online if the citation is to one of the more than 200 journals hosted by HighWire (http://highwire.stanford.edu) without a subscription to that journal. There are also direct links from references to the Medline abstract for other titles.

www.jech.com 